\title{
Impaired longitudinal deformation measured by speckle-tracking echocardiography in children with end-stage renal disease
}

\author{
Maike van Huis $^{1}$ • Nikki J. Schoenmaker ${ }^{1}$ - Jaap W. Groothoff ${ }^{1}$ • \\ Johanna H. van der Lee ${ }^{2} \cdot$ Maria van Dyk $^{3} \cdot$ Marc Gewillig $^{4} \cdot$ Linda Koster ${ }^{5}$.

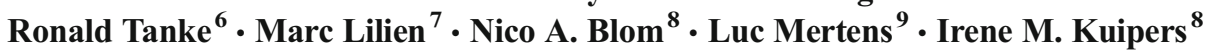

Received: 14 September 2015 /Revised: 13 February 2016/Accepted: 15 February 2016/Published online: 17 May 2016

(C) The Author(s) 2016. This article is published with open access at Springerlink.com

\begin{abstract}
Background Left ventricular dysfunction is an important comorbidity of end-stage renal disease (ESRD) and is associated with a poor prognosis in the adult population. In pediatric ESRD, left ventricular function is generally well preserved, but limited information is available on early changes in myocardial function. The aim of this study was to investigate myocardial mechanics in pediatric patients with ESRD using speckle-tracking echocardiography (STE).

Methods Echocardiographic studies, including M-mode, tissue Doppler imaging (TDI) and STE, were performed in 19 children on dialysis, 17 transplant patients and 33 agematched controls. Strain measurements were performed from the apical four-chamber and the short axis view, respectively. Results The interventricular and left ventricular posterior wall thickness was significantly increased in dialysis and transplant patients compared to healthy controls. No significant differences were found in shortening fraction, ejection fraction and systolic tissue Doppler velocities. Dialysis and transplant pa-
\end{abstract}

Maike van Huis

maikevanhuis@gmail.com

1 Department of Pediatric Nephrology, Emma Children's Hospital, Academic Medical Center (AMC) Amsterdam/University of Amsterdam, Amsterdam, The Netherlands

2 Pediatric Clinical Research Office, Emma Children's Hospital, Academic Medical Center Amsterdam, Amsterdam, The Netherlands

3 Department of Pediatric Nephrology, University Hospital Leuven, Leuven, Belgium

4 Department of Pediatric Cardiology, University Hospital Leuven, Leuven, Belgium tients had a decreased mean longitudinal strain compared to healthy controls, with a mean difference of 3.1 [95\% confidence interval (CI) 2.0-4.4] and 2.7 (95\% CI 1.2-4.2), respectively. No differences were found for radial and circumferential strain.

Conclusions Speckle-tracking echocardiography may reveal early myocardial dysfunction in the absence of systolic dysfunction measured by conventional ultrasound or TDI in children with ESRD.

Keywords Cardiovascular Imaging · Pediatric · Systolic dysfunction $\cdot$ Longitudinal strain $\cdot$ Children

\section{Introduction}

Cardiovascular disease is highly prevalent in children and adults with end-stage renal disease (ESRD) and has been

5 Department of Pediatric Nephrology, University Medical Center (UMC) St. Radboud/Radboud University,

Nijmegen, The Netherlands

6 Department of Pediatric Cardiology, UMC St. Radboud/Radboud University, Nijmegen, The Netherlands

7 Department of Pediatric Nephrology, Wilhelmina Children's Hospital, UMC Utrecht/Utrecht University, Utrecht, The Netherlands

8 Department of Pediatric Cardiology, Emma Children's Hospital, AMC Amsterdam/University of Amsterdam, Amsterdam, The Netherlands

9 Cardiology, The Hospital for Sick Children, The University of Toronto, Toronto, ON, Canada 
shown to be one of the main causes of mortality [1-4]. In young adults with ESRD, left ventricular hypertrophy (LVH) and impaired systolic function are found even at early stages of chronic kidney disease (CKD) [5-10]. In children with ESRD, systolic LV function generally seems to be well preserved, as described in observational studies using twodimensional (2D) echocardiography and tissue Doppler measurements $[7,11]$.

Newer echocardiographic techniques, such as speckletracking echocardiography (STE), allow the study of myocardial deformation and myocardial mechanics [12-14]. STE has been used to describe early changes in myocardial mechanics prior to changes in the ejection fraction (EF). Studies in adults and children exposed to anthracyclines have shown that changes in longitudinal strain can be observed prior to changes in EF [15-17]. The same has been described in children with Duchenne cardiomyopathy [18]. In adults with CKD, a deterioration in renal function (estimated glomerular filtration rate) has been shown to be associated with a decline in strain values [19, 20], while in adults with ESRD, a decreased longitudinal strain has been shown to be a significant risk factor for all-cause mortality [21]. The aim of the study reported here was to identify early changes in myocardial mechanics in pediatric patients with ESRD using STE as the imaging modality.

\section{Methods}

\section{Subjects}

This is a multicenter prospective cohort study which recruited patients, aged 0-19 years, in three academic medical centers $(\mathrm{AMC})$ in the Netherland (Emma Children's Hospital AMC Amsterdam, Radboud University AMC and University Medical Center Utrecht) between 1 October 2007 and 1 April 2015. Children with a congenital heart disease were excluded. These three centers are involved in the Renal Insufficiency therapy in Children-Quality assessment and improvement (RICH-Q) project, in which all Dutch and Belgian centers providing pediatric renal replacement therapy (RRT) collaborate to improve the quality of care [22].

Controls were selected from a database of healthy Dutch children without any medical history who had been evaluated at the cardiology department of the respective AMC for a benign murmur, a positive family history of structural cardiac abnormalities or miscellaneous complaints that proved to be non-cardiac. The groups were matched for age. We assessed prevalence of hypertension in the patients, with hypertension defined as a blood pressure (BP) measurement of $>95$ th percentile on at least three occasions based on gender, age and height according to the Fourth Report on the Diagnosis, Evaluation, and treatment of High Blood Pressure in
Children and Adolescents [23], irrespective of use of antihypertensives. The body mass index $Z$-score was calculated based on gender and age according to the 2000 Centers for Disease Control and Prevention growth charts [24].

\section{Echocardiographic measurements}

Echocardiographic assessment in patients undergoing hemodialysis (HD) was performed after a HD session.

All children were studied using the Vivid 7 ultrasound system (GE Medical Systems, GE Healthcare Life Sciences, Pittsburgh, PA) using a standardized protocol. Measurements of LV size and function were performed according to the guidelines published by the American Society of Echocardiography [25]. M-mode echocardiography was performed from the parasternal long axis views. Assessment of LV dimensions included: end-diastolic interventricular septum thickness (IVSd), LV end-diastolic and end-systolic diameter (LVEDd and LVED, respectively) and diastolic LV posterior wall thickness (LVPWd). The shortening fraction (SF) (\%) was calculated. The LV mass index (LVMI) was calculated according to the Devereux formula, including a correction for height indexed to the power of 2.7 [26]. LVH was defined as an LVMI $\left(\mathrm{g} / \mathrm{m}^{2.7}\right)$ of $>95$ th percentile according to the normal values for age and gender published by Khoury et al. [26]. Early and late mitral valve inflow velocities (E and A, respectively) were measured from the apical four-chamber view and the E/A ratio calculated. Each variable was measured three times, and the mean was calculated. Pulsed-wave tissue Doppler imaging (TDI) images were obtained from the apical four-chamber view. Tissue Doppler tracings were measured in the basal interventricular septum (IVS) and the basal LV lateral wall. Peak systolic ( $\left.\mathrm{s}^{\prime}\right)$ and early diastolic $\left(\mathrm{e}^{\prime}\right)$ velocities were measured in three consecutive cycles and averaged for both IVS (IVS s') and basal LV wall (LV s'). Septal E/e' and mitral $\mathrm{E} / \mathrm{e}^{\prime}$ ratios were calculated. The ejection fraction $(\mathrm{EF})$ was measured from the two-chamber and four-chamber views using the biplane Simpson's method.

2D grayscale images were acquired in the parasternal apical four-chamber view at a frame rate of between 70 and 90 frames per second [27]. Three consecutive cardiac cycles were acquired. Off-line analysis was performed using the EchoPac workstation (GE Medical Systems). Briefly, the endocardial border was manually traced at end systole (starting at mid-septum for the short axis and at the basal septum from the apical four-chamber view). Tracking was automatically performed, and the analysis was accepted after visual inspection and when the software indicated adequate tracking. If tracking was suboptimal the endocardial border was retraced. Lagrangian radial $\varepsilon$ and strain rate (SR) curves and circumferential $\varepsilon$ curves from the short-axis view (6 segments: anterior septum, anterior, lateral, posterior, inferior and septum) and 
longitudinal $\varepsilon$ curves from the apical four-chamber view (6 segments: basal septum, mid septum, apical septum, apical lateral, mid lateral and basal lateral) were obtained. The automated timing of aortic valve closure was used, and end-systolic strain values were measured. Mean longitudinal strain (LS), radial strain (RS) and circumferential strain (CS) were obtained by calculating the average strain values measured in each myocardial region (Fig. 1). LS is a negative value and thus represents shortening. A less negative, i.e. a 'higher' value, indicates less shortening, indicative of worse systolic LV function.

To assess the intra-observer variability of the STE measurements, the same observer-blinded to the groups-re-analyzed 25 echocardiograms, ten from ESRD patients and 15 from healthy controls, after a period of at least 2 weeks.

a

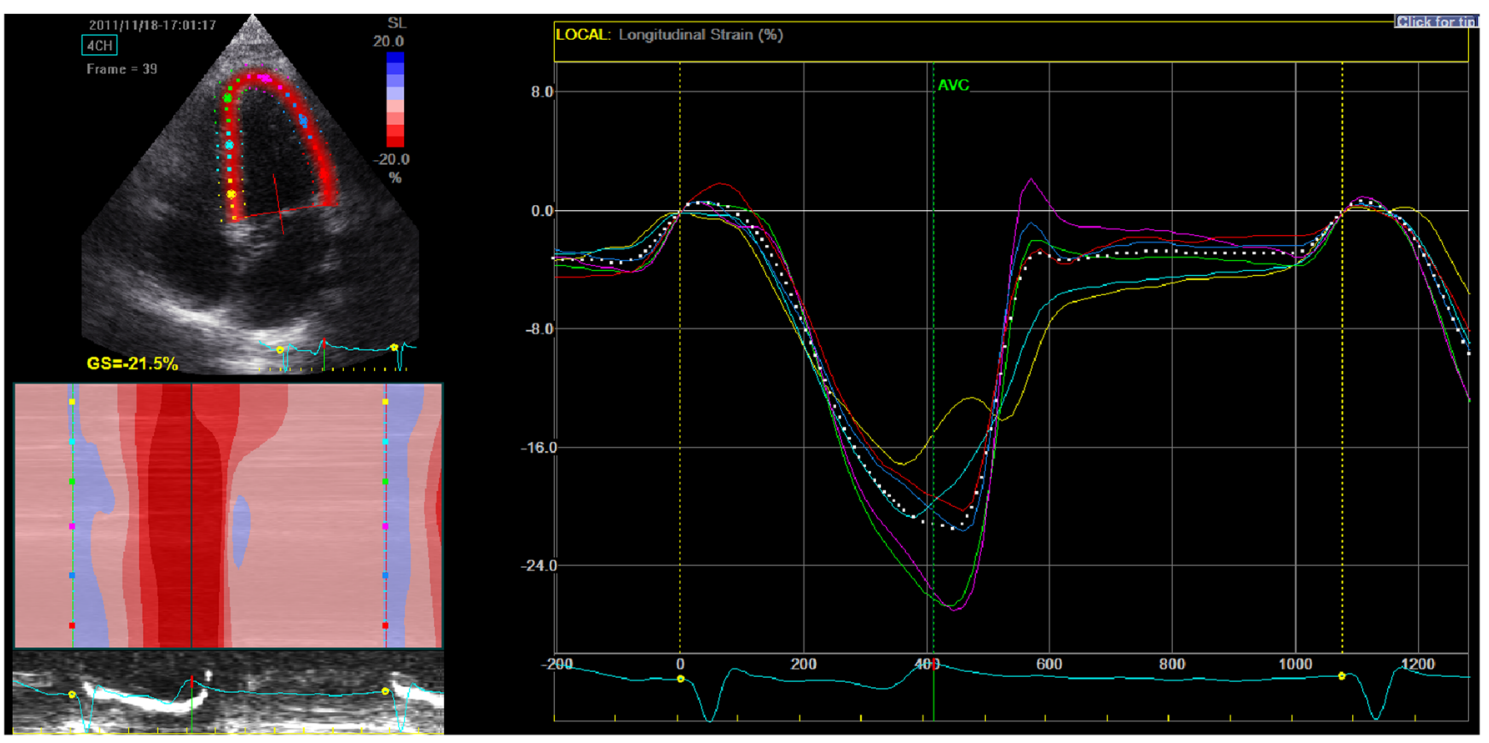

b

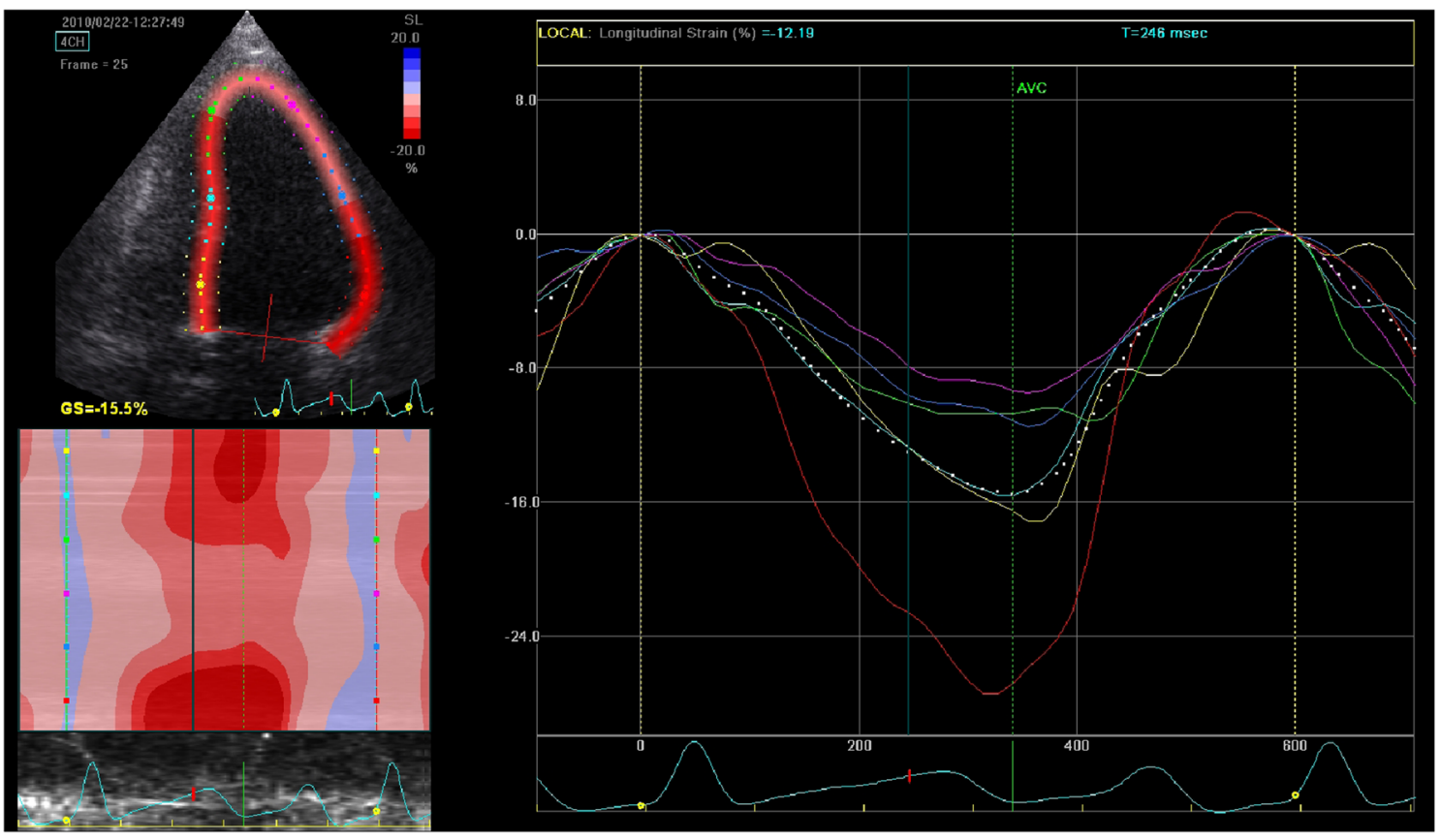

Fig. 1 Two-dimensional speckle-tracking echocardiography (STE) for left ventricular (LV) longitudinal strain (LS) in a healthy control subject (a) and a child with end-stage renal disease (ESRD) (b). The mean LS (white dotted line) is the mean of the six segments of the myocardium of the left ventricle, (e.g. yellow basal septum, light blue mid septum, green apical septum, red basal lateral, dark blue mid lateral, purple apical lateral). The mean LS can be seen to be significantly lower in the child with ESRD (b) than in the healthy control subject (a) 


\section{Statistical analysis}

All analyses were performed using SPSS ver. 22.0 for Windows statistical software (IBM Corp., Armonk, NY). Values are presented as mean \pm standard deviation unless stated otherwise. An independent samples $t$ test or MannWhitney test was used to compare the means of continuous variables when appropriate. Categorical values were compared using the chi-square test or Fisher exact test, where indicated. To assess intra-observer reproducibility, we calculated the coefficient of variation (CV) as the ratio of the standard deviation of the differences of the repeated measurements and the mean of all measurements in all individuals (grand mean). The CV gives an indication of the measurement error as a percentage of the mean value in the study population. Parameters related to systolic function were compared between the ESRD and the control group using multiple linear regression analysis to adjust for confounding. Potential confounders were age, gender and body surface area (BSA). If the regression coefficient of the central determinant 'ESRD' changed by $>10 \%$ after the addition of a particular variable to the regression model, this variable was considered to be a confounder and kept in the final model. Patients on dialysis and transplantation therapy were compared in order to assess the influence of RRT modality. Linear regression was used to analyze the association between total duration on RRT and echocardiographic measurements.

\section{Results}

Measurements obtained in 36 children with ESRD and 33 healthy control subjects were analyzed. At the time of the echocardiography, 19 children were on dialysis (15 on HD and 4 on peritoneal dialysis) and 17 were transplant recipients. Of the 17 transplant recipients, 11 (65\%) had been on dialysis before this study. The median time on RRT at the time of the echocardiography was 1.4 (range 0.0-15.6) and 2.7 (range 0.1-4.8) years for the patients on dialysis and renal transplant recipients, respectively. The median time between transplantation and echocardiography was 13 (range 0.3-40) months. Eight $(42 \%)$ patients on dialysis and six patients $(35 \%)$ with a renal transplant were diagnosed with arterial hypertension. The characteristics of the children on dialysis, the transplant recipients and the healthy controls are shown in Table 1.

\section{Diastolic function}

The E/A ratio did not differ significantly between the patients and healthy controls. TDI measurements were available in 16 children on dialysis, 15 transplant recipients and 27 healthy controls (Table 2). After adjustment for BSA, both children on dialysis and transplant recipients had significantly lower $\mathrm{e}^{\prime}$ values in the IVS and LV lateral basal segments, resulting in increased $\mathrm{E} / \mathrm{e}^{\prime}$ ratios in both segments which did not, however, reach statistical significance.

\section{Systolic function}

Systolic function in the patients, as measured with TDI (IVS s' and LVS $s^{\prime}$ ), did not differ significantly from that of the healthy controls (Table 2).

Table 3 summarizes the results of the LV dimensions, LV $\mathrm{SF}$ and LV mass. There was no difference in SF or EF between the patients and controls. After adjustment for BSA and age, there was a significant effect of dialysis and transplant status on LVMI, which was increased in children on dialysis and transplanted children compared to healthy controls. LVH was diagnosed in $4(21 \%)$ of the dialysis children and 4 $(24 \%)$ of the transplant recipients.

\section{Speckle-tracking echocardiography}

There were no significant differences between the repeated measurements: the CV of LS was $3 \%$, and the mean difference between measurements was 0.2 [95\% confidence interval (CI) -1.5 to 1.9]. Table 4 summarizes the longitudinal, radial and circumferential strain measurements. The mean LS was significantly reduced in patients on dialysis and after renal transplant when compared with the controls, with a mean difference between the dialysis and transplantation groups versus controls of 3.1 [95\% CI 2.0-4.4] and 2.7 [95 $\%$ CI 1.2-4.2] respectively (both $P<0.001$ ). The RS and CS measurements did not differ significantly between the patient groups and the controls, with a mean difference between the RS in the dialysis and transplantation groups versus controls of 0.5 [ $95 \% \mathrm{CI}-8.2$ to 7.1$]$ and 5.0 [ $95 \% \mathrm{CI}-2.6$ to 12.6 ], respectively. The mean difference between the CS in the dialysis and transplantation groups versus the controls was 0.5 [95 $\%-1.7$ to 2.8 ] and 0.5 [95\%-1.9 to 2.9$]$, respectively. LS decreased with 0.05 per unit increase of LVMI, but it did not differ between patients with and patients without LVH (mean difference of -1.0 [ -3.4 to 1.5$]$.

\section{Influence of RRT and presence of hypertension}

There were no significant differences between the renal transplant and the dialysis groups with respect to conventional echocardiographic measurements, TDI or STE measurements (Tables 2, 3, 4). No significant association was found between total duration of RRT and the echocardiographic parameters. LS and LVMI did not differ between patients with and without hypertension. The mean difference in LS and LVMI for patients with and without hypertension was $1.1[95 \% \mathrm{CI}-2.4$ to $1.9]$ and 4.2 [ -7.3 to 9.9$]$, respectively. 
Table 1 General characteristics of the study population

\begin{tabular}{|c|c|c|c|c|c|c|}
\hline \multirow[t]{2}{*}{ General characteristics } & \multicolumn{3}{|l|}{ Study population } & \multicolumn{3}{|l|}{$P$ value } \\
\hline & Dialysis $(n=19)$ & $\begin{array}{l}\text { Transplant } \\
\text { recipients }(n=17)\end{array}$ & $\begin{array}{l}\text { Healthy controls } \\
(n=33)\end{array}$ & $\begin{array}{l}\text { Dialysis vs. healthy } \\
\text { controls }\end{array}$ & $\begin{array}{l}\text { Transplant recipients } \\
\text { vs. healthy controls }\end{array}$ & $\begin{array}{l}\text { Dialysis vs. transplant } \\
\text { recipients }\end{array}$ \\
\hline Male & $12(63 \%)$ & $12(70 \%)$ & $16(49 \%)$ & $0.78^{\mathrm{a}}$ & $0.08^{\mathrm{a}}$ & $0.45^{\mathrm{a}}$ \\
\hline Hypertension & $8(42 \%)$ & $6(35 \%)$ & $0(0 \%)$ & $<0.001^{\mathrm{a}}$ & $0.001^{\mathrm{a}}$ & $0.74^{\mathrm{a}}$ \\
\hline RRT duration (years) & $1.4[0.0-15.6]$ & $2.7[0.1-4.8]$ & - & - & - & $0.30^{\mathrm{b}}$ \\
\hline GFR $\left(\mathrm{ml} / \mathrm{min} / 1.73 \mathrm{~m}^{2}\right)$ & $7.9[4.0-27.0]$ & $60.3[7.2-95.7]$ & - & - & - & - \\
\hline Hemoglobin (mmol/l) & $6.7[5.3-8.0]$ & $7.2[5.4-8.5]$ & - & - & - & 0.07 \\
\hline $\operatorname{BSA}\left(m^{2}\right)$ & $1.3 \pm 0.4$ & $1.3 \pm 0.4$ & $1.4 \pm 0.4$ & $0.67^{\mathrm{b}}$ & $0.63^{\mathrm{b}}$ & $0.85^{\mathrm{b}}$ \\
\hline BMI $Z$-score & $-0.1[-3.1$ to 1.6$]$ & $0.7[-1.0$ to 2.6$]$ & $0.2[-3.8$ to 1.7$]$ & $0.12^{\mathrm{b}}$ & $0.21^{\mathrm{b}}$ & $0.03^{\mathrm{b}}$ \\
\hline Age (years) & $15.1[1.2-17.9]$ & $13.7[4.6-18.4]$ & $12.5[2.4-18.3]$ & $0.24^{\mathrm{b}}$ & $0.47^{\mathrm{b}}$ & $0.89^{\mathrm{b}}$ \\
\hline
\end{tabular}

Values in table are presented as the median with the range in square brackets, a number $(n)$ with the percentage in parenthesis or the mean \pm standard deviation (SD)

$R R T$ renal replacement therapy, GFR glomerular filtration rate (calculated according to the 2009 Schwartz formula), $B S A$ body surface area (according to the Dubois and Dubois formula), BMI body mass index

${ }^{\text {a }}$ Fisher's exact test

b Mann-Whitney U test

\section{Discussion}

Our study demonstrates that in pediatric patients with ESRD, longitudinal LV strain was significantly lower in both dialysis and renal graft recipients compared with normal controls, while radial and circumferential function were not different. Also, SF and EF were generally normal. These findings suggest that in children with ESRD, LV systolic performance assessed by EF is generally normal, whereas STE detects changes in longitudinal deformation and diastolic function.

In hypertensive patients, diastolic dysfunction precedes systolic function [28], and this has been described previously in pediatric ESRD [10, 29, 30]. We found decreased e'-velocities, suggestive of reduced early relaxation and increased E/e' ratio which could indicate higher filling pressures in the patients. The increased filling pressures could be related to volume status or represent reduced LV compliance and may be caused by uremic toxins inducing an inflammatory response or be related to the maladaptive hypertrophic response in this patient population group [31]. Thse hypotheses need further study by cardiac magnetic resonance imaging or other imaging modalities.

In ESRD, hypertension and uremic factors are independently associated with both LVH and ventricular dysfunction [32]. Hypertension in non-uremic patients can either lead to concentric hypertrophy with normal or even increased $\mathrm{EF}$ in early stages or to eccentric hypertrophy [33]. Apparent systolic dysfunction occurs only in advanced stages of hypertension-induced LVH. In adult ESRD patients, however, systolic dysfunction may occur at a relative early stage, most likely as a result of myocardial fibrosis induced by chronic inflammation or in direct response to uremic toxins. This fibrosis is an important trigger of electric myocardial instability and hence arrhythmia [32]. In addition, endothelial dysfunction, another hallmark of ESRD, may lead to an inadequate vasodilatory response in the thickened left ventricle and subsequently local ischemia, hereby further enhancing fibrosis [34]. Consequently, the absence of systolic dysfunction based on EF assessment may result in an underestimation of the existence of important systolic myocardial changes by the uremic milieu.

In our patients, although there was an increased LVMI and hence ventricular hypertrophy, no systolic dysfunction was found with conventional echocardiography (normal SF and EF) and with TDI (IVS s' and LVS s'). Nevertheless, STE showed a decreased LS in our patients, suggesting that longitudinal function is reduced in the patient group, while radial and circumferential function is preserved. LV concentric hypertrophy is mainly caused by hypertrophic response in the mid-myocardial layers, which are mainly more circumferentially oriented. This compensates for the reduction in longitudinal function and can explain the preserved EF. Changes in longitudinal function with preserved EF have been described in other disease populations, mainly in patients with LVH [35]. Hothi et al. [36] described a decreased LS in children on dialysis with preservation of global function.

Our findings are consistent with data obtained in hypertensive adults as reported by Imbalzano et al. [37]. In patients with hypertension, the changes are most prominent in the basal part of the IVS. A decrease in longitudinal function precedes changes in circumferential and radial function in patients with LVH due to pressure overload, whereas in hypertrophic cardiomyopathy or systemic disease, not only longitudinal, but also radial strain can be impaired [35]. In our 
study, LV mass increased in $21 \%$ of the dialysis patients and $24 \%$ of the renal transplant patients, suggesting some degree of LVH, but the presence of LVH did not seem to be a risk factor for the decrease in LS, in turn suggesting that the changes in strain can be present in ESRD patients in the absence of LVH. However, it should be noted that the measurement of LVH in pediatric ESRD has already been shown to be less reliable, as demonstrated by Schoenmaker et al. [38].

In ESRD, volume overload and myocardial ischemia induced by HD can cause mechanical dyssynchrony by imbalances in the stretching and shortening of myocardial fibers, which results in a pathological STE pattern that may affect systolic function [39, 40]. Cardiac fibrosis is highly prevalent in patients with ESRD, but the origin and mechanisms of fibrosis in the heart are have not yet been completely elucidated [41-43]. In addition, in patients with CKD, myocardial dysfunction is not merely the result of cardiac remodeling; especially in dialysis patients, impaired myocardial reserve may induce recurrent myocardial stunning and hence myocardial dysfunction. In ESRD, high serum phosphate levels, high fibroblast growth factor 23 (FGF23) levels and low serum Klotho levels are considered to play a role in cardiac hypertrophy and cardiac fibrosis. High serum FGF23 levels are primarily associated with $\mathrm{LVH}$, whereas low serum Klotho levels and hyperphosphatemia are associated with endothelial dysfunction, atherosclerosis and fibrosis [41, 44]. It is possible that high serum phosphate levels and low serum Klotho levels may independently of high FGF23 levels induce cardiac fibrosis, resulting in dyssynchronous myocardial function. However, this hypothesis is not supported by our data.

As previously described, changes in longitudinal myocardial function with preserved $\mathrm{EF}$ have been described in other disease populations, as well as in adult ESRD patients $[15,16$, $20,45-47]$. In a recent systematic review and meta-analysis in adults (mean age $>60$ years), global LS was considered to have a superior prognostic value to $\mathrm{EF}$ for predicting major adverse cardiac events [45]. Furthermore, LS has been shown to be significantly associated with all-cause mortality in adults with chronic ischemic cardiomyopathy [hazard ratio 1.69 (95 $\%$ CI 1.33-2.15) per $5 \%$ increase; $p<0.001$ ] [48]. Whether a reduction in LS can be used as a specific predictor of cardiovascular morbidity and mortality in children with ESRD remains to be established. This will require longitudinal followup studies in children with ESRD.

We found no significant differences in echocardiography measurements between children on dialysis and those on a functioning graft, nor did we find significant associations between duration on RRT and echocardiographic measurements. This suggests that duration of dialysis does not influence cardiac performance. However, we were unable to draw conclusions from our analysis of the association between dialysis vintage and cardiac phenotype as our study population was too heterogeneous. 


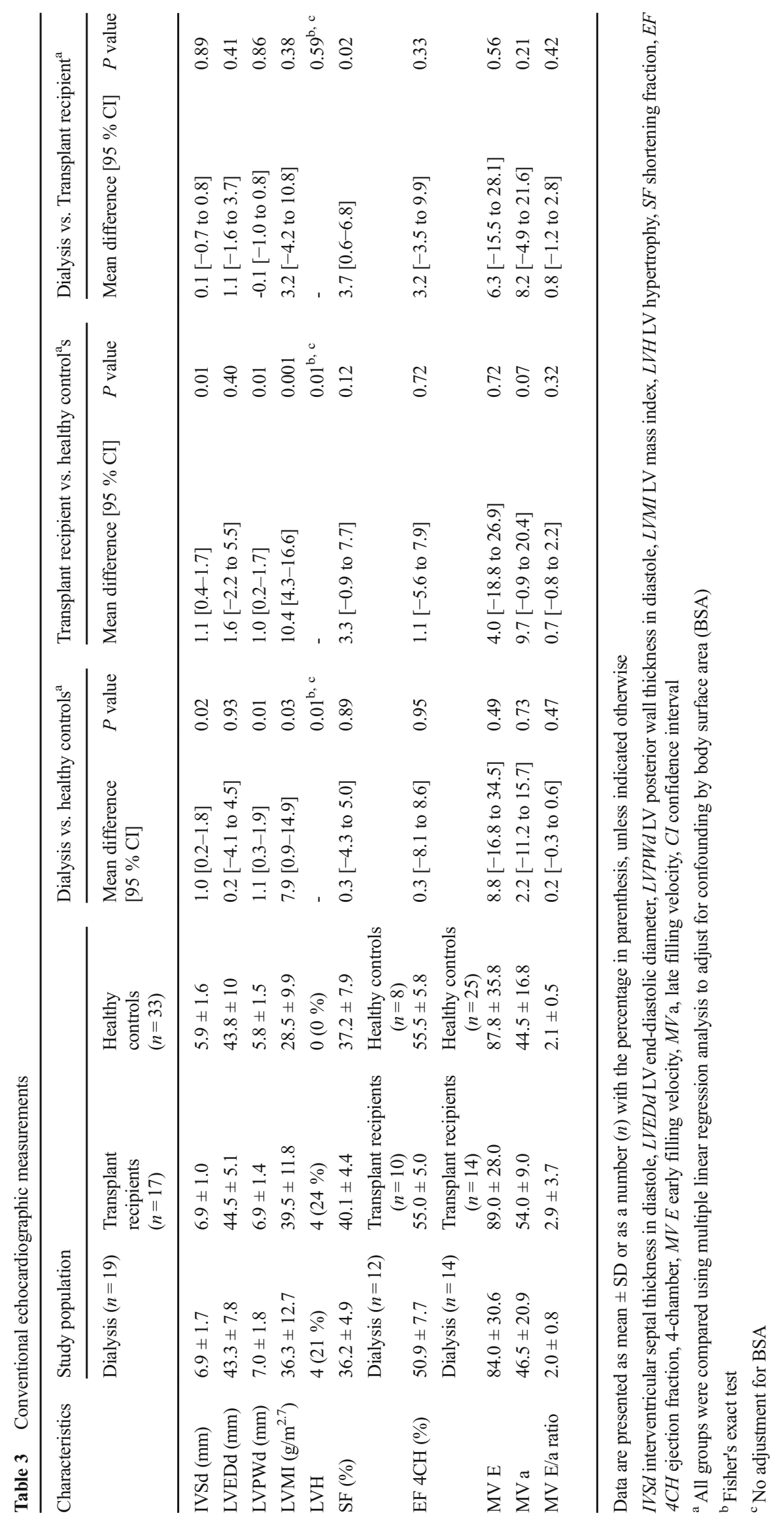


Table 4 Speckle Tracking measurements

\begin{tabular}{|c|c|c|c|c|c|c|c|c|c|}
\hline \multirow[b]{2}{*}{ Characteristics } & \multirow[t]{2}{*}{ Dialysis } & \multirow[t]{2}{*}{$\begin{array}{l}\text { Transplant } \\
\text { recipients }\end{array}$} & \multirow[t]{2}{*}{$\begin{array}{l}\text { Healthy } \\
\text { controls }\end{array}$} & \multicolumn{2}{|c|}{$\begin{array}{l}\text { Dialysis vs. healthy } \\
\text { controls }^{\mathrm{a}}\end{array}$} & \multicolumn{2}{|c|}{$\begin{array}{l}\text { Transplant recipients } \\
\text { vs. healthy controls }\end{array}$} & \multicolumn{2}{|c|}{$\begin{array}{l}\text { Dialysis vs. transplant } \\
\text { recipients }^{\mathrm{a}}\end{array}$} \\
\hline & & & & $\begin{array}{l}\text { Mean difference } \\
{[95 \% \mathrm{CI}]}\end{array}$ & $P$ value & $\begin{array}{l}\text { Mean difference } \\
{[95 \% \mathrm{CI}]}\end{array}$ & $P$ value & $\begin{array}{l}\text { Mean difference } \\
{[95 \% \mathrm{CI}]}\end{array}$ & $P$ value \\
\hline Longitudinal strain (\%) & $n=19$ & $n=17$ & $n=33$ & & & & & & \\
\hline Basal septum & $-15.2 \pm 3.4$ & $-16.8 \pm 2.6$ & $-15.4 \pm 2.5$ & & & & & & \\
\hline Mid septum & $-18.9 \pm 2.4$ & $-19.5 \pm 1.9$ & $-20.1 \pm 1.8$ & & & & & & \\
\hline Apical septum & $-20.2 \pm 5.3$ & $-19.6 \pm 4.5$ & $-23.0 \pm 4.0$ & & & & & & \\
\hline Basal lateral & $-17.0 \pm 5.0$ & $-15.2 \pm 5.4$ & $-18.8 \pm 5.6$ & & & & & & \\
\hline Mid lateral & $-15.0 \pm 5.4$ & $-15.2 \pm 6.0$ & $-19.8 \pm 3.3$ & & & & & & \\
\hline Apical lateral & $-17.0 \pm 5.1$ & $-16.8 \pm 7.5$ & $20.6 \pm 4.9$ & & & & & & \\
\hline $\begin{array}{l}\text { Mean Longitudinal } \\
\text { strain }\end{array}$ & $-16.6 \pm 2.8$ & $-16.7 \pm 3.4$ & $-19.4 \pm 2.1$ & $3.1[2.0-4.4]$ & $<0.001$ & $2.7[1.2-4.2]$ & 0.001 & $0.4[-1.7$ to 2.5$]$ & 0.68 \\
\hline Radial strain (\%) & $n=16$ & $n=17$ & $n=33$ & & & & & & \\
\hline Basal septum & $18.0 \pm 9.8$ & $25.1 \pm 14.6$ & $22.6 \pm 10.7$ & & & & & & \\
\hline Mid septum & $19.8 \pm 13.9$ & $20.4 \pm 13.2$ & $17.9 \pm 15.7$ & & & & & & \\
\hline Apical septum & $27.1 \pm 21.0$ & $26.9 \pm 16.7$ & $19.1 \pm 19.5$ & & & & & & \\
\hline Basal lateral & $14.6 \pm 12.1$ & $21.3 \pm 21.7$ & $17.9 \pm 10.5$ & & & & & & \\
\hline Mid lateral & $28.5 \pm 21.2$ & $29.6 \pm 18.8$ & $24.1 \pm 13.8$ & & & & & & \\
\hline Apical lateral & $37.5 \pm 29.3$ & $35.7 \pm 18.1$ & $30.6 \pm 23.8$ & & & & & & \\
\hline Mean radial strain & $24.3(14.5)$ & $26.5 \pm 13.3$ & $22.0 \pm 12$ & $0.5[-8.2$ to 7.1$]$ & 0.88 & $5.0[-2.6$ to 12.6$]$ & 0.19 & $4.6[-4.5$ to 13.7$]$ & 0.31 \\
\hline $\begin{array}{l}\text { Circumferential } \\
\text { strain }(\%)\end{array}$ & $n=16$ & $n=15$ & $n=33$ & & & & & & \\
\hline Basal septum & $21.0 \pm 6.8$ & $24.2 \pm 5.3$ & $21.2 \pm 5.2$ & & & & & & \\
\hline Mid septum & $15.7 \pm 5.9$ & $21.5 \pm 7.3$ & $17.5 \pm 6.0$ & & & & & & \\
\hline Apical septum & $13.7 \pm 6.0$ & $15.5 \pm 5.4$ & $15.5 \pm 4.9$ & & & & & & \\
\hline Basal lateral & $21.3 \pm 5.0$ & $21.2 \pm 4.4$ & $21.8 \pm 3.9$ & & & & & & \\
\hline Mid lateral & $17.0 \pm 5.9$ & $16.2 \pm 5.0$ & $16.8 \pm 6.3$ & & & & & & \\
\hline Apical lateral & $15.2 \pm 7.7$ & $12.5 \pm 6.1$ & $14.5 \pm 6.5$ & & & & & & \\
\hline $\begin{array}{l}\text { Mean } \\
\text { circumferential strain }\end{array}$ & $17.3 \pm 3.4$ & $17.9 \pm 4.1$ & $17.4 \pm 4.0$ & $0.5[-1.7$ to 2.8$]$ & 0.65 & 0.5 [-1.9 to 2.9$]$ & 0.66 & $1.0[-1.7$ to 3.6$]$ & 0.45 \\
\hline
\end{tabular}

Data in table are presented as the mean $\pm \mathrm{SD}$, unless indicated otherwise

CI confidence interval

${ }^{a}$ All groups were compared using multiple linear regression analysis to adjust for confounding by body surface area (BSA)

\section{Limitations}

The major limitation of this study is the small sample size. The study was limited to the three hospitals in the RICH-Q project where the same ultrasound equipment was used, as we wanted to avoid the effect of inter-machine variability on the measurements. Machines of different vendors produce different values for speckle-tracking strain-derived parameters [49] and, consequently, comparison is more difficult. Despite adopting a prospective protocol, we were unable to acquire all data prospectively from all patients because some images were of poor quality, limiting the number of available scans. Adjustment of echocardiographic measurements to body size in our population was challenging as many ESRD patients had a shorter height and smaller BSA compared to age-matched controls.
We were not able to assess inter-observer variability; however a recent study has shown a good reproducibility of strain measurements with low inter- and intra-observer relative mean errors, with lower errors than for $\mathrm{EF}$ and most other conventional echocardiographic parameters [50].

\section{Conclusion}

We found a decreased LS, suggestive of systolic dysfunction in pediatric ESRD patients, while systolic function measured both by conventional echocardiography and TDI was preserved. STE may reveal early myocardial dysfunction in the absence of systolic dysfunction in ESRD children. The long-term importance of these findings warrants further investigation and follow-up. 
Acknowledgments This study was performed as part of the RICH-Q project, which is mainly funded by the Dutch Kidney Foundation. Additional funding was provided by Astellas, Ferring Pharmaceuticals, Sanofi, Roche and Shire. The funders had no role in the design and conduct of the project, data gathering or interpretation, or in the preparation of the manuscript. We are grateful to all patients and the participating centers in the RICH-Q study. We kindly thank Prof. Dr. Laura Bennet for her comments on the earlier version of this manuscript.

Compliance with ethical standards The research ethics boards of all participating hospitals approved the study. Written informed consent was obtained from the parents and/or the patients.

\section{Financial disclosure None}

Conflict of interest All authors declare that they have no conflicts of interest regarding this work

Open Access This article is distributed under the terms of the Creative Commons Attribution 4.0 International License (http:// creativecommons.org/licenses/by/4.0/), which permits unrestricted use, distribution, and reproduction in any medium, provided you give appropriate credit to the original author(s) and the source, provide a link to the Creative Commons license, and indicate if changes were made.

\section{References}

1. Groothoff J, Gruppen M, de Groot E, Offringa M (2005) Cardiovascular disease as a late complication of end-stage renal disease in children. Perit Dial Int 25[Suppl 3]:S123-126

2. Groothoff JW (2005) Long-term outcomes of children with endstage renal disease. Pediatr Nephrol 20:849-853

3. Gruppen MP, Groothoff JW, Prins M, van der Wouw P, Offringa M, Bos WJ, Davin JC, Heymans HS (2003) Cardiac disease in young adult patients with end-stage renal disease since childhood: a Dutch cohort study. Kidney Int 63:1058-1065

4. McDonald SP, Craig JC (2004) Long-term survival of children with end-stage renal disease. N Engl J Med 350:2654-2662

5. Chinali M, de Simone G, Matteucci MC, Picca S, Mastrostefano A, Anarat A, Caliskan S, Jeck N, Neuhaus TJ, Peco-Antic A, Peruzzi L, Testa S, Mehls O, Wuhl E, Schaefer F (2007) Reduced systolic myocardial function in children with chronic renal insufficiency. $\mathrm{J}$ Am Soc Nephrol 18:593-598

6. Foley RN, Parfrey PS, Harnett JD, Kent GM, Martin CJ, Murray DC, Barre PE (1995) Clinical and echocardiographic disease in patients starting end-stage renal disease therapy. Kidney Int 47: 186-192

7. Johnstone LM, Jones CL, Grigg LE, Wilkinson JL, Walker RG, Powell HR (1996) Left ventricular abnormalities in children, adolescents and young adults with renal disease. Kidney Int 50:9981006

8. Matteucci MC, Wuhl E, Picca S, Mastrostefano A, Rinelli G, Romano C, Rizzoni G, Mehls O, de Simone G, Schaefer F (2006) Left ventricular geometry in children with mild to moderate chronic renal insufficiency. J Am Soc Nephrol 17:218-226

9. Mitsnefes MM, Kimball TR, Border WL, Witt SA, Glascock BJ, Khoury PR, Daniels SR (2004) Impaired left ventricular diastolic function in children with chronic renal failure. Kidney Int 65:14611466

10. Mitsnefes MM, Kimball TR, Kartal J, Witt SA, Glascock BJ, Khoury PR, Daniels SR (2006) Progression of left ventricular hypertrophy in children with early chronic kidney disease: 2-year follow-up study. J Pediatr 149:671-675

11. Palcoux JB, Palcoux MC, Jouan JP, Gourgand JM, Cassagnes J, Malpuech G (1982) Echocardiographic patterns in infants and children with chronic renal failure. Int J Pediatr Nephrol 3:311-314

12. Amundsen BH, Helle-Valle T, Edvardsen T, Torp H, Crosby J, Lyseggen E, Stoylen A, Ihlen H, Lima JA, Smiseth OA, Slordahl SA (2006) Noninvasive myocardial strain measurement by speckle tracking echocardiography: validation against sonomicrometry and tagged magnetic resonance imaging. J Am Coll Cardiol 47:789793

13. Bohs LN, Trahey GE (1991) A novel method for angle independent ultrasonic imaging of blood flow and tissue motion. IEEE Trans Biomed Eng 38:280-286

14. Mondillo S, Galderisi M, Mele D, Cameli M, Lomoriello VS, Zaca V, Ballo P, D'Andrea A, Muraru D, Losi M, Agricola E, D'Errico A, Buralli S, Sciomer S, Nistri S, Badano L (2011) Speckle-tracking echocardiography: a new technique for assessing myocardial function. J Ultrasound Med 30:71-83

15. Fallah-Rad N, Walker JR, Wassef A, Lytwyn M, Bohonis S, Fang T, Tian G, Kirkpatrick ID, Singal PK, Krahn M, Grenier D, Jassal DS (2011) The utility of cardiac biomarkers, tissue velocity and strain imaging, and cardiac magnetic resonance imaging in predicting early left ventricular dysfunction in patients with human epidermal growth factor receptor II-positive breast cancer treated with adjuvant trastuzumab therapy. J Am Coll Cardiol 57:22632270

16. Poterucha JT, Kutty S, Lindquist RK, Li L, Eidem BW (2012) Changes in left ventricular longitudinal strain with anthracycline chemotherapy in adolescents precede subsequent decreased left ventricular ejection fraction. J Am Soc Echocardiogr 25:733-740

17. Sawaya H, Sebag IA, Plana JC, Januzzi JL, Ky B, Cohen V, Gosavi S, Carver JR, Wiegers SE, Martin RP, Picard MH, Gerszten RE, Halpern EF, Passeri J, Kuter I, Scherrer-Crosbie M (2011) Early detection and prediction of cardiotoxicity in chemotherapy-treated patients. Am J Cardiol 107:1375-1380

18. Mertens L, Ganame J, Claus P, Goemans N, Thijs D, Eyskens B, Van Laere D, Bijnens B, D'Hooge J, Sutherland GR, Buyse G (2008) Early regional myocardial dysfunction in young patients with Duchenne muscular dystrophy. J Am Soc Echocardiogr 21: 1049-1054

19. Liu YW, Su CT, Huang YY, Yang CS, Huang JW, Yang MT, Chen JH, Tsai WC (2011) Left ventricular systolic strain in chronic kidney disease and hemodialysis patients. Am J Nephrol 33:84-90

20. Yan P, Li H, Hao C, Shi H, Gu Y, Huang G, Chen J (2011) 2Dspeckle tracking echocardiography contributes to early identification of impaired left ventricular myocardial function in patients with chronic kidney disease. Nephron Clin Pract 118:c232-c240

21. Kramann R, Erpenbeck J, Schneider RK, Rohl AB, Hein M, Brandenburg VM, van Diepen M, Dekker F, Marx N, Floege J, Becker M, Schlieper G (2014) Speckle tracking echocardiography detects uremic cardiomyopathy early and predicts cardiovascular mortality in ESRD. J Am Soc Nephrol 25:2351-2365

22. Renal Insufficiency therapy in Children-Quality assessment and improvement (RICH-Q) study. Available at: [https://www.rich-q.nl]

23. National High Blood Pressure Education Program Working Group on High Blood Pressure in Children and Adolescents (2004) The fourth report on the diagnosis, evaluation, and treatment of high blood pressure in children and adolescents. Pediatrics 114[2 Suppl 4th Report]:555-576

24. Kuczmarski RJ, Ogden CL, Guo SS, Grummer-Strawn LM, Flegal KM, Mei Z, Wei R, Curtin LR, Roche AF, Johnson CL (2002) 2000 CDC Growth Charts for the United States: methods and development. Vital Health Stat 11:1-190

25. Lai WW, Geva T, Shirali GS, Frommelt PC, Humes RA, Brook MM, Pignatelli RH, Rychik J, Task Force of the Pediatric Council 
of the American Society of Echocardiography, Pediatric Council of the American Society of Echocardiography (2006) Guidelines and standards for performance of a pediatric echocardiogram: a report from the Task Force of the Pediatric Council of the American Society of Echocardiography. J Am Soc Echocardiogr 19:14131430

26. Khoury PR, Mitsnefes M, Daniels SR, Kimball TR (2009) Agespecific reference intervals for indexed left ventricular mass in children. J Am Soc Echocardiogr 22:709-714

27. Korinek J, Wang J, Sengupta PP, Miyazaki C, Kjaergaard J, McMahon E, Abraham TP, Belohlavek M (2005) Twodimensional strain-a Doppler-independent ultrasound method for quantitation of regional deformation: validation in vitro and in vivo. J Am Soc Echocardiogr 18:1247-1253

28. Slama M, Susic D, Varagic J, Frohlich ED (2002) Diastolic dysfunction in hypertension. Curr Opin Cardiol 17:368-373

29. Schoenmaker NJ, Kuipers IM, van der Lee JH, Tromp WF, van Dyck M, Gewillig M, Blom NA, Groothoff JW (2014) Diastolic dysfunction measured by tissue Doppler imaging in children with end-stage renal disease: a report of the RICH-Q study. Cardiol Young 24:236-244

30. Ten Harkel AD, Cransberg K, Van Osch-Gevers M, Nauta J (2009) Diastolic dysfunction in paediatric patients on peritoneal dialysis and after renal transplantation. Nephrol Dial Transplant 24:1987-1991

31. Zoccali C, Benedetto FA, Mallamaci F, Tripepi G, Giacone G, Cataliotti A, Seminara G, Stancanelli B, Malatino LS (2001) Prognostic impact of the indexation of left ventricular mass in patients undergoing dialysis. J Am Soc Nephrol 12:2768-2774

32. Scharer K, Schmidt KG, Soergel M (1999) Cardiac function and structure in patients with chronic renal failure. Pediatr Nephrol 13: 951-965

33. Santos M, Shah AM (2014) Alterations in cardiac structure and function in hypertension. Curr Hypertens Rep 16:428

34. Hajhosseiny R, Khavandi KF, Goldsmith DJ (2013) Cardiovascular disease in chronic kidney disease: untying the Gordian knot. Int $\mathrm{J}$ Clin Pract 67:14-31

35. Cikes M, Sutherland GR, Anderson LJ, Bijnens BH (2010) The role of echocardiographic deformation imaging in hypertrophic myopathies. Nat Rev Cardiol 7:384-396

36. Hothi DK, Rees L, McIntyre CW, Marek J (2013) Hemodialysisinduced acute myocardial dyssynchronous impairment in children. Nephron Clin Pract 123:83-92

37. Imbalzano E, Zito C, Carerj S, Oreto G, Mandraffino G, CusmàPiccione M, Di Bella G, Saitta C, Saitta A (2011) A Left ventricular function in hypertension: new insight by speckle tracking echocardiography. Echocardiography 28:649-657

38. Schoenmaker NJ, van der Lee JH, Groothoff JW, van Iperen GG, Frohn-Mulder IM, Tanke RB, Ottenkamp J, Kuipers IM (2013) Low agreement between cardiologists diagnosing left ventricular hypertrophy in children with end-stage renal disease. BMC Nephrol 14:170

39. Lagies R, Beck BB, Hoppe B, Sheta SS, Weiss V, Sreeram N, Udink Ten Cate FE (2015) Inhomogeneous longitudinal cardiac rotation and impaired left ventricular longitudinal strain in children and young adults with end-stage renal failure undergoing hemodialysis. Echocardiography 32:1250-1260

40. Murata T, Dohi K, Onishi K, Sugiura E, Fujimoto N, Ichikawa K, Ishikawa E, Nakamura M, Nomura S, Takeuchi H, Nobori T, Ito M (2011) Role of haemodialytic therapy on left ventricular mechanical dyssynchrony in patients with end-stage renal disease quantified by speckle-tracking strain imaging. Nephrol Dial Transplant 26:16551661

41. Hu MC, Shi M, Cho HJ, Adams-Huet B, Paek J, Hill K, Shelton J, Amaral AP, Faul C, Taniguchi M, Wolf M, Brand M, Takahashi M, Kuro OM, Hill JA, Moe OW (2015) Klotho and phosphate are modulators of pathologic uremic cardiac remodeling. J Am Soc Nephrol 26:1290-1302

42. Mirza MA, Larsson A, Melhus H, Lind L, Larsson TE (2009) Serum intact FGF23 associate with left ventricular mass, hypertrophy and geometry in an elderly population. Atherosclerosis 207: 546-551

43. Przybylowski P, Wasilewski G, Janik L, Kozlowska S, Nowak E, Malyszko J (2014) Fibroblast growth factor 23 and Klotho as cardiovascular risk factors in heart transplant recipients. Transplant Proc 46:2848-2851

44. Scialla JJ, Wolf M (2014) Roles of phosphate and fibroblast growth factor 23 in cardiovascular disease. Nat Rev Nephrol 10:268-278

45. Kalam K, Otahal P, Marwick TH (2014) Prognostic implications of global LV dysfunction: a systematic review and meta-analysis of global longitudinal strain and ejection fraction. Heart 100:16731680

46. Popovic ZB, Kwon DH, Mishra M, Buakhamsri A, Greenberg NL, Thamilarasan M, Flamm SD, Thomas JD, Lever HM, Desai MY (2008) Association between regional ventricular function and myocardial fibrosis in hypertrophic cardiomyopathy assessed by speckle tracking echocardiography and delayed hyperenhancement magnetic resonance imaging. J Am Soc Echocardiogr 21:1299-1305

47. Wang H, Liu J, Yao XD, Li J, Yang Y, Cao TS, Yang B (2012) Multidirectional myocardial systolic function in hemodialysis patients with preserved left ventricular ejection fraction and different left ventricular geometry. Nephrol Dial Transplant 27:4422-4429

48. Bertini M, Ng AC, Antoni ML, Nucifora G, Ewe SH, Auger D, Marsan NA, Schalij MJ, Bax JJ, Delgado V (2012) Global longitudinal strain predicts long-term survival in patients with chronic ischemic cardiomyopathy. Circ Cardiovasc Imaging 5:383-391

49. Koopman LP, Slorach C, Hui W, Manlhiot C, McCrindle BW, Friedberg MK, Jaeggi ET, Mertens L (2010) Comparison between different speckle tracking and color tissue Doppler techniques to measure global and regional myocardial deformation in children. J Am Soc Echocardiogr 23:919-928

50. Farsalinos KE, Daraban AM, Unlu S, Thomas JD, Badano LP, Voigt JU (2015) Head-to-head comparison of global longitudinal strain measurements among nine different vendors: The EACVI/ ASE Inter-Vendor Comparison Study. J Am Soc Echocardiogr 28: $1171-1181$ 